Marek Zgorzelski

\title{
THE AEOLIAN LANDSCAPES OF HIGH MOUNTAINS
}

Landscapes, which develop under the influence of wind, are commonly being associated with the classical deserts, with the bars and dunes of the sea-coasts, with the vast outwash fields, or with the river valleys and proglacial valleys appearing among the lowland glacial areas. Conform to the method of actualism, in force nowadays in the sciences of the Earth, the results of the study of the aeolian processes and forms, conducted at present in the dry environments, are juxtaposed with the similar palaeomorphological elements, registered currently in other types of environments. This kind of actualisation indicates that the sickle-shaped barhan dunes, namely - the ones moving with their arms forward, are characteristic for the extremely dry, plantless environments, with deep groundwater levels, while the parabolic dunes, that is - the ones moving with their front forward, are proper for the environments, into which, owing, in particular, to the shallower groundwater resources, vegetation enters. This regularity could have been considered correct for all the recognised aeolian landscapes, were it not for the observations of the effects of the accumulative activity of winds in high mountains, mainly in Himalayas, and in Ladakh, Zanskar and Transhimalaya mountains.*

The sickle-shaped barhan dunes belong to the most popular dune forms of the high mountains. They reach the height of several to a couple of dozen metres. Mountain barhans arise on the outwash cones situated in the intermontane lows, located high in the mountains, and in the wider stretches of the valleys, accompanying their crossings, like in the western part of the Southern Tibet (in Transhimalayas), as well as on the ridge planation surfaces, like in the Fiery Mountains of the Turfan Valley. Mountain barhans may appear individually or in greater numbers, forming dune fields. In some of the mountain dales barhans are overlaid on the surface of the boggy or peaty mountain tundra. The movement of these dunes takes place here with the arms forward - and not with the front forward - even in conditions of the developing vegetation cover, or in conditions of the seasonally increased humidity of the bedding, and thus contradicts the theories mentioned before. This apparently atypical behaviour of the mountain barhans can be explained by the following factors:

* Photographs by the author. 
- occurrence of the long lasting, very strong and gusty winds, especially following the growing season, when the tundra surface around the dune is completely frozen;

- intensive drying of the loose sand surfaces by the wind, which is not conducive to the freezing through of the sediments in the dune-covered zones;

- limitation of the possibilities of plant growth during the growing seasons by the strong winds in the zones of intensive blowing (vegetation develops not in the neighbourhood of the dune arms, but on the areas remaining in the wind shade, that is - first of all inside the dune arcs; in the dunecovered zones of Transhimalayas the yak pastures are usually located within the dune arcs).

In the light of these facts the views on the emergence of a part of the inland dunes on the post-glacial areas should perhaps be verified.

The aeolian processes and forms accompany also - and maybe first of all - the mountain deserts. While the main features of the typical deserts are the excess of evaporation over the supply of humidity and a very scarce share of the biological life in the functioning of the ecosystems, the mountain deserts are primarily characterised by the latter feature.

The following types can be distinguished among the mountain deserts:

— ice-and-snow deserts;

- stone deserts;

- gravel deserts;

- sandy deserts.

The particular types of mountain deserts appear on the definite floors of the mountain ranges. The sandy and gravel deserts appear on the bottoms of the vast river valleys and of the intermontane dales, at the fluvial and glaciofluvial floors. The stone deserts appear on the surfaces recently left by the glaciers, at the post-glacial floor. The ice-and-snow deserts are proper for the glacial floor.

Valley dunes dominate on the sandy and gravel deserts. They exist on the high, almost entirely devoid of plants, terraces of the large rivers of Karakorum and Transhimalayas, for instance in the valleys of Indus, Shyok, and Yarlung Tsangpo (in India: Brahmaputra). The dominating forms among them are of the type of the active mountain barhans, which move according to the directions of winds locally dominating on the particular segments of the valleys. These dunes often accompany the wider stretches of the main valleys, associated with the outwash cones entering into the valleys, and in such cases the movement of the rock matter caused by the wind factor is transversal with respect to the river and glacial transport direction.

Sand walls having the length of several dozen to several hundred metres and the height of a couple to several tens of metres may also emerge in the mountain dales. Their height, starting with the windward side, increases along with the length. They have evenly inclined, steep slopes, and a flat upper (planation) surface. Such forms arise owing to the dismemberment of the mountain barhans by the wind. 


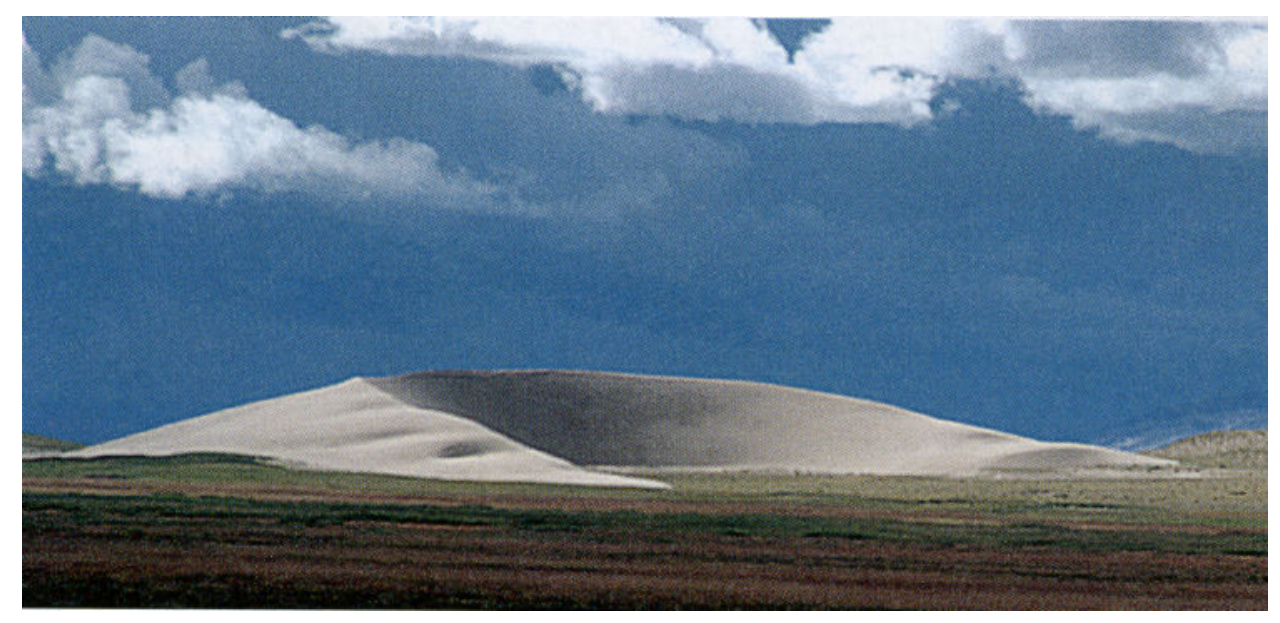

Fig. 1, Fig. 1a. A barhan-type dunes in one of the dales of the Transhimalayas.

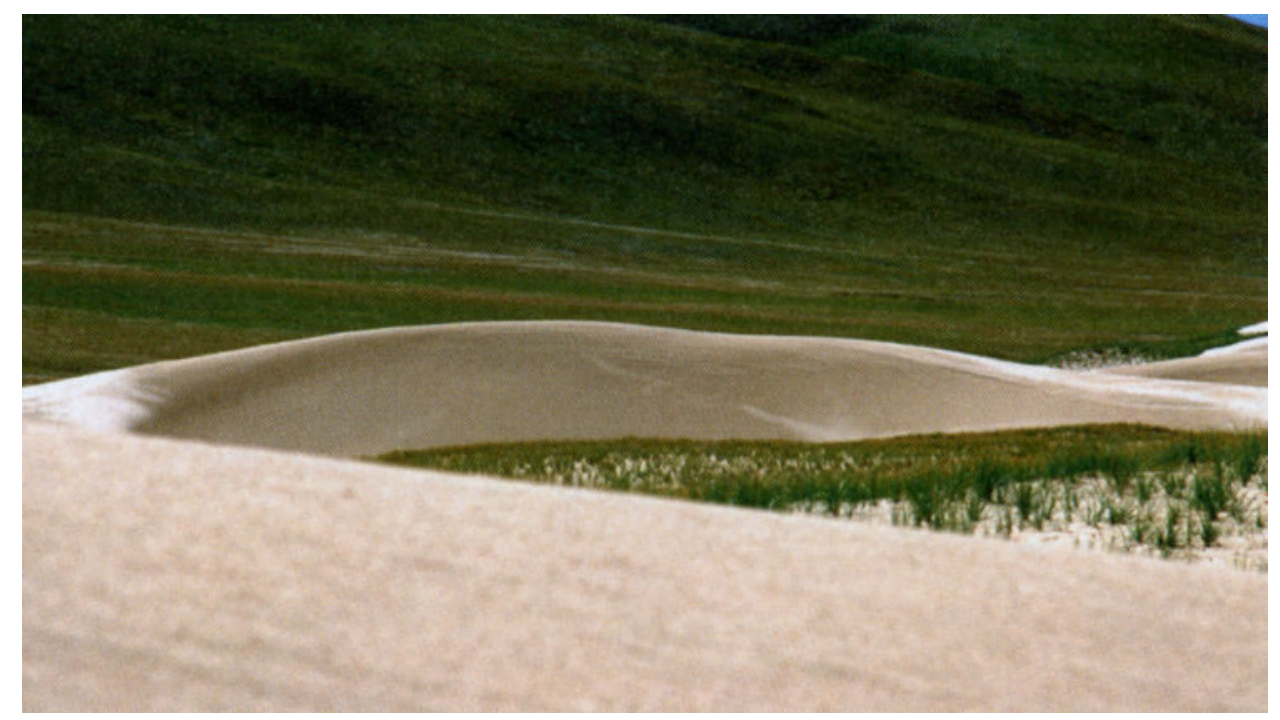




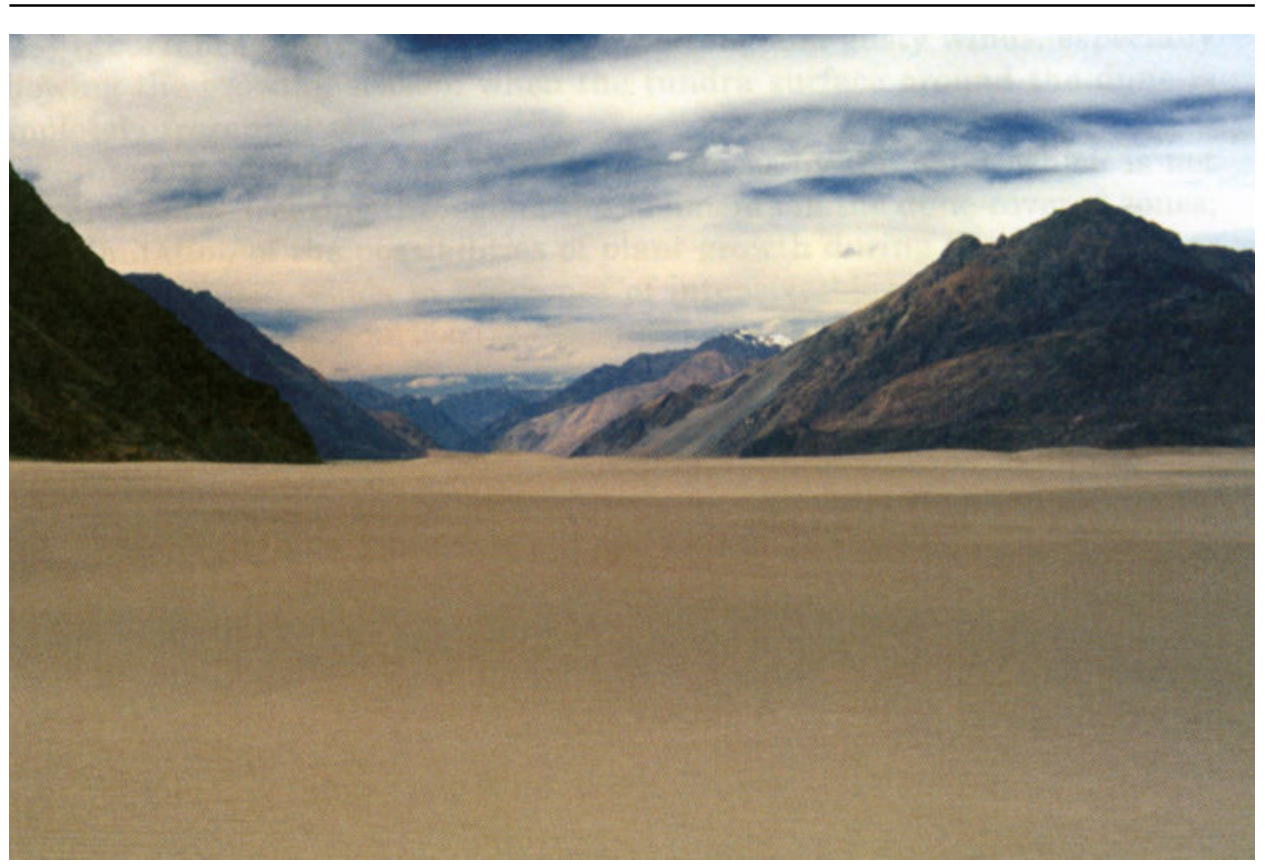

Fig. 2. Sandy-gravel desert in the bottom of the Shyok river.

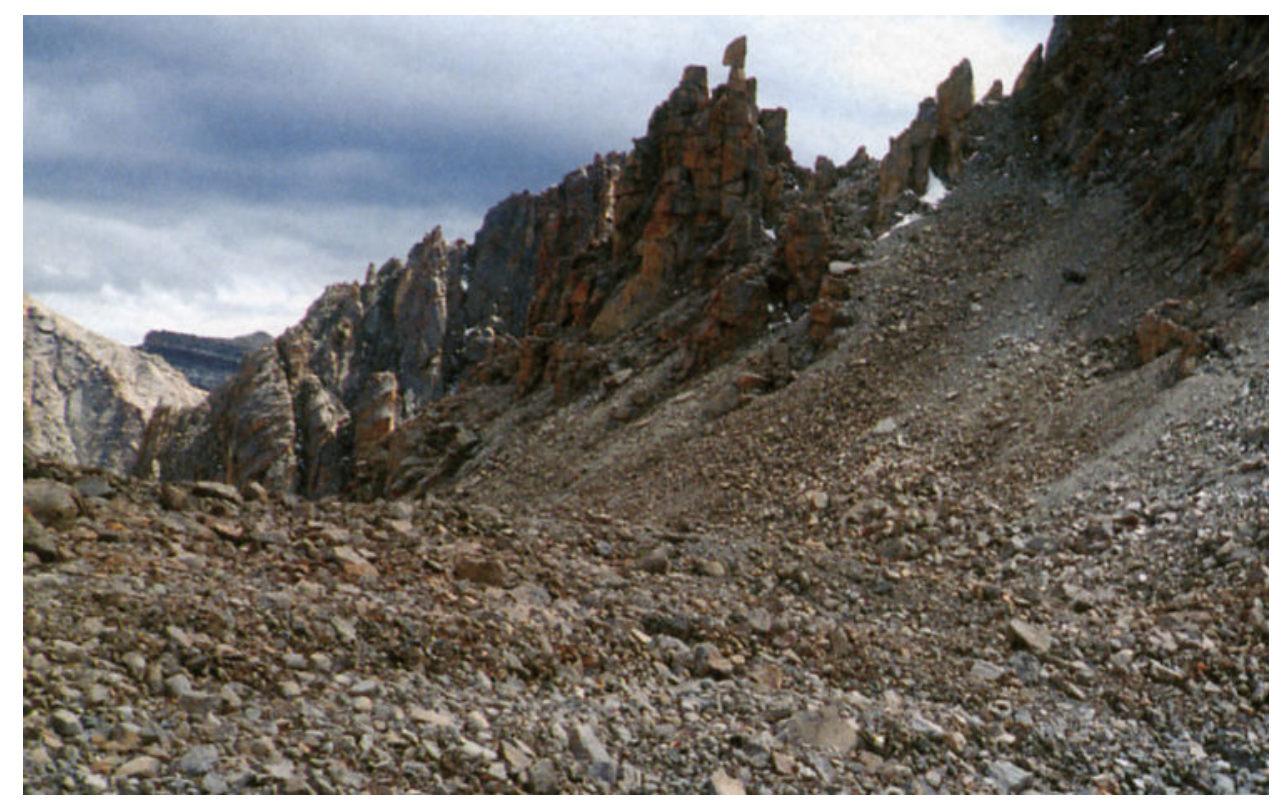

Fig. 3. Stone desert in the Kailash range. 
Barrier dunes constitute, as well, an interesting aeolian form. They represent a type of mountain barhans and usually arise in the lower parts of the smaller valleys, close to their openings into the mountain dales, which gather the sandy material. These dunes, of several dozens of metres of height, cross the valleys like barriers. The sand, blown into the valley from the dale, accumulates in the valley bottom, initially in the form of a dune mound hampering the outflow of water. By the very same, water gathering before the dune limits further movement of the front, and the arcs of the arms develop reaching the slopes of the valley. The developing dune becomes at the same time an obstacle for the wind, which is pushed underneath the slopes of the valley, where, in the space between the arms and the slopes, it significantly increases its velocity, and thereby also its morphological effectiveness. Hence, the sand, which continues to be supplied to the valley, is already transported from the front of the dune along the outside lines of its arms and farther under the slopes of the valley, which causes stretching of the barhan arms deeper into the valley. A deflation gully develops between the arm of the barhan and the slope of the valley. It gradually disappears deeper in the valley owing to the progressing filling with the aeolian material. In this manner an under-slope dune terrace takes shape, composed of the barhan arm and the cover filling the gully. A significant contribution to the buildup of the terrace comes also from the sediments originating from the degradation of the slope, overlapping or intermittent with the aeolian covers. The latter case occurs more often, because the cycles of the increased aeolian activity do not coincide with the cycles of the more intensive transport of the matter along the slopes.

An equally surprising element of the aeolian landscape is constituted by the gravel dunes. It is commonly accepted that dunes are made of loose sands. And so it usually is. Yet, cases are known of appearance of strong, gusty winds, such that break the trees, destroy the electric supply posts, lift the roofs of houses and the cars. Hence, it should not be astonishing at all, especially in conditions of high mountains, that the wind might transport gravel or small pebbles. The dunes, and in particular the mountain barhans, as well as the wall and mound forms, which develop through transformation of the dunes, composed of gravel, even of the coarse gravel, are a frequently encountered element in some mountain valleys and dales. An instance is constituted here by the valley of the Shyok river, flowing between Ladakh and Karakorum mountains. The dune mounds and the typical barhans of the height of a couple metres, composed of pebbles having diameters of up to several centimetres, glued together by the dust, can also be encountered in the Turfan Valley.

Side by side with the here mentioned atypical elements of the aeolian relief, the floor of the sandy and gravel deserts contains also the plains of the overblown sands, as well as deflation gullies or bowls of various shapes and magnitudes, which are often accompanied by the aeolian rings, that is - the frames of the lows, appearing as the walls of a couple of dozen centimetres of height, composed of gravel, pebbles or boulders. When such walls develop only on the windward side of the bowl, this is an evidence for 
a directional course of winds and the horizontal transport of the rocky matter, but when, on the other hand, they surround the low entirely, we deal with a whirling movement of the air, lifting the grains upwards. If we encounter the frame of a long gully, this will be an evidence for the activity of the moving air whirl, furrowing the bedding and laying off the material lifted at the borders of the low thus being established.

Mountain dunes are being created not just in the bottoms of the valleys. Slope dunes are, namely, very popular in the mountains of Tibet, in Transhimalayas, in Zanskar, and in Ladakh. They take the shape of walls or linked arcs, and cover large fragments of mountain slopes in the form of regular frills. It is hard to distinguish among them definite dynamical types, since the same forms might once be barhans, and at other times - parabolic dunes. They develop under the simultaneous action of wind and the gravitation forces. Wind blows the sand from the valley onto the slopes (the dunes move then like barhans, that is - with their arms up the slope), while the force of gravity causes its pouring down, or sliding of the main mass of the sand down the slope (the dunes start to move then like the parabolic forms, that is - with their fronts downhill). This leads to appearance of the parallel dune ridges, oriented conform to the slope line. The dunes, however, move more often across the slopes transversally to the downhill direction. Yet, in case of occurrence of a high seasonal variability of the wind directions with respect to the valley axis, their movement might get stopped and the analogous parallel ridges might form. In the situation, when the effects of the wind and the force of gravity are equilibrated, the well-developed ledges of the dune terraces may appear on the slopes. The ensembles of this kind of forms are very frequent in Transhimalayas and in Ladakh.

Pass dunes may develop on the higher floors of the mountains. These are rather small forms, ranging from several tens of centimetres to $2-3$ metres of height. Regular hillocks or small walls, situated perpendicularly to the line of the pass and located closer to its windward part, usually in the vicinity of the slopes falling down to the pass, dominate among these forms. Depending upon the location of the pass with respect to the climate and vegetation floors these dunes may either be active forms, or stabilised by the vegetation. Such forms, usually of the permanent type, can be encountered on some Himalayan passes, like in the vicinity of Solo Khumbu, while in the as yet impermanent form - on the lower passes of Ladakh, onto which the sand from the higher terraces of the Indus valley is blown (in this case the dunes appear in the central part of the saddle and on its windward side).

An interesting element of the landscape of the old, dry mountains, located inside the Asian continent, is constituted by the ridge (top) dunes, formed as extensive barhans. Their height exceeds sometimes 100 metres, and they appear on the top planation surfaces. The dunes occupy in some cases the entire surface of the mountaintop, and the sand pouring from them covers the upper parts of the rocky slopes. They were observed in the Fiery Mountains at the border of the Turfan Valley. 


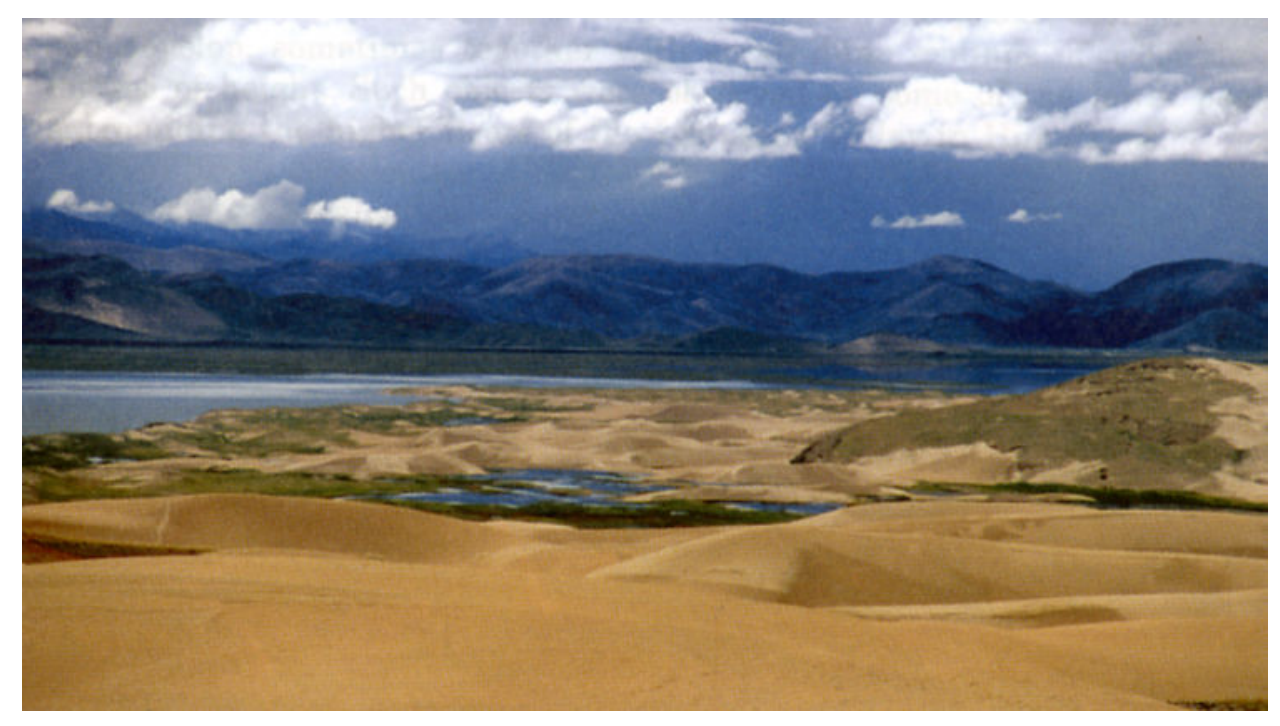

Fig. 4. A dune area in Transhimalayas.

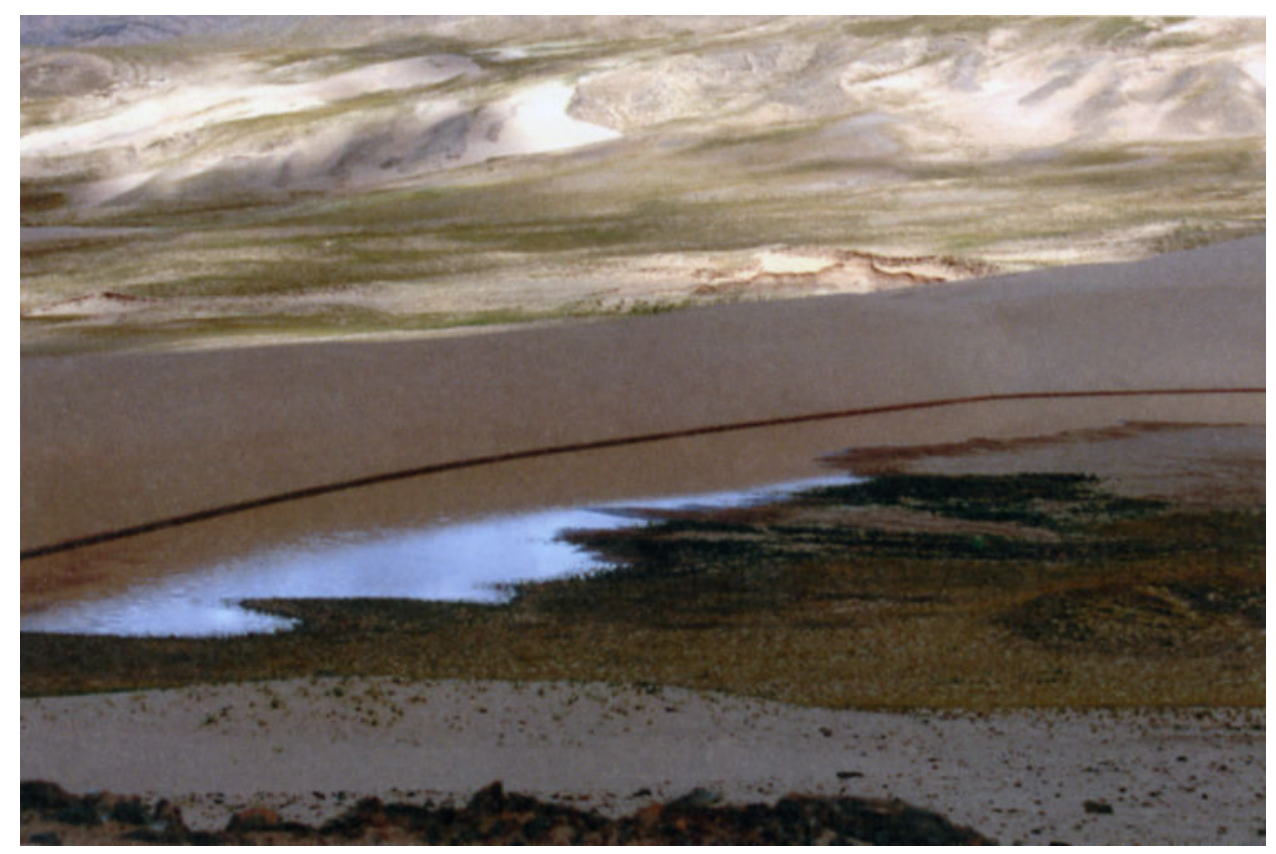

Fig. 5. A barrier dune in Transhimalayas. 


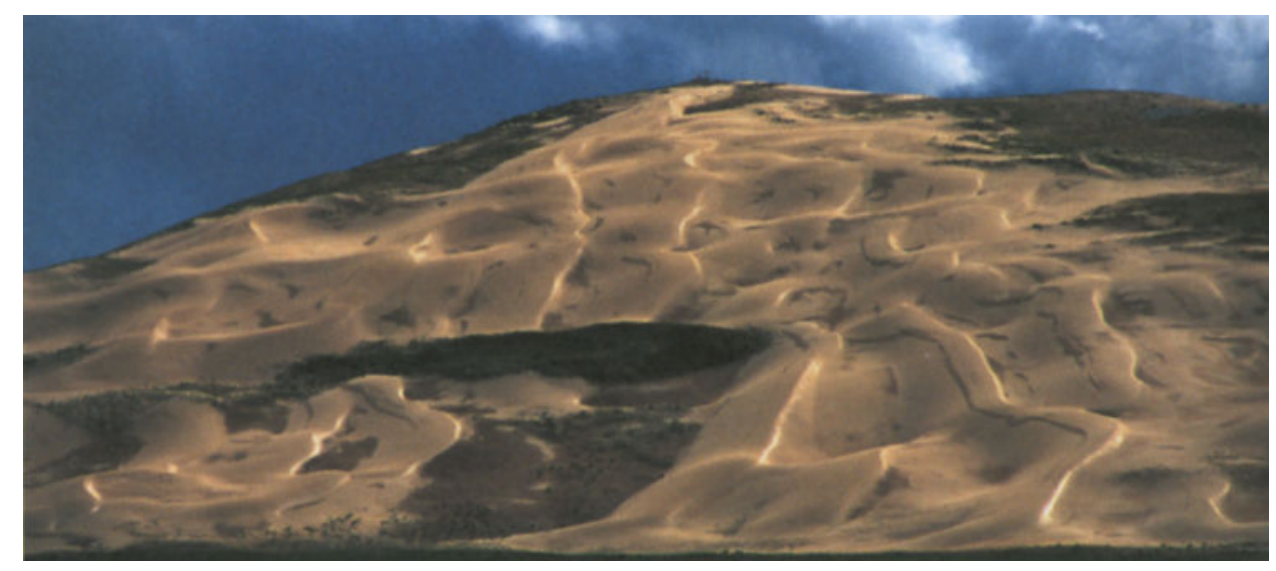

Fig. 6. Slope dunes in Transhimalayas.

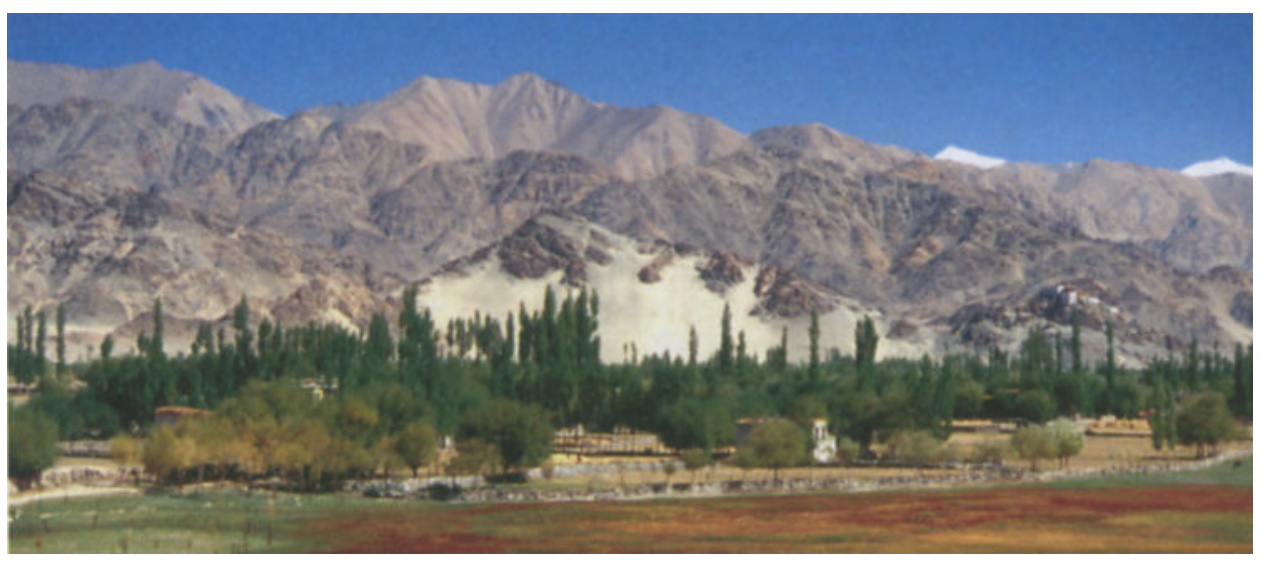

Fig. 7. Slope dunes in Ladakh. 
Under the advantageous circumstances, that is - in the situation when the peaks reaching $5-6,000 \mathrm{~m}$ a.s.l. are in the precipitation shade of the yet higher mountains, but not in their wind shade, or in the extremely dry mountains, on the plateau below the peak, or on the flat peaks, aeolian covers can develop, sometimes together with small dune mounds of a couple of metres of height. Such objects were observed on some of the lower peaks surrounding the higher floors of the Langtang Valley in Himalayas.

One should mention yet the snow dunes. Although these are impermanent forms, they leave their traces in the landscape. In their original shape they remind of barhans or walls transversal with respect to the wind direction, built of the snow crystals. As the local field obstacles, even though of limited dimensions, however, they force the settling (behind the obstacle) of the mineral matter blown by the wind. This type of seasonal forms of a dozen or so centimetres of height have been observed in the Polish Table Mts.

The observations reported here have been made by the author during numerous trips to the high mountains of Central Asia, including Himalayas and Transhimalayas, Ladakh and Zanskar, Central Tibet, Kashgar Dale, as well as Tien-Shan Mts. 